\title{
HUBUNGAN DUKUNGAN KELUARGA DENGAN KEJADIAN KECEMASAN POSTPARTUM
}

\author{
The Relationship of Family Support With The Post Partum Anxiety \\ Juliana Widyastuti Wahyuningsih \\ Akbid Budi Mulia Palembang \\ (yuliana_widyastuti@ymail.com)
}

\begin{abstract}
ABSTRAK
Latar Belakang : Kecemasan postpartum masih menjadi masalah masyarakat di Indonesia dan serig tidak terdeteksi karena minimnya pelaporan. Kecemasan ini mengakibatkan gangguan pada psikologis ibu, mengganggu hubungan dengan suami dan anak, gangguan pada pertumbuhan dan perkembangan bayi.

Tujuan Penelitian : Penelitian ini bertujuan untuk mengetahui hubungan antara dukungan keluarga dengan kejadian kecemasan postpartum.

Metode : Penelitian deskriptif korelasi ini dilakukan dengan cross sectional. Populasi penelitian ini adalah semua ibu pasca bersalin di Klinik Bersalin Budi Mulia Medica pada bulan September sampai dengan bulan Oktober 2018 dengan jumlah 120 orang, teknik sampling yang digunakan adalah Accidental Sampling dimana saat penelitian dijumpai responden sebanyak 27 responden. Data diambil menggunakan data primer dan data sekunder. Alat pengumpulan data berupa kuesioner. Analisa data univariat dan bivariat dengan menggunakan kendall tau.

Hasil : Berdasarkan uji Kendal Tau didapatkan nilai $\tau=-0,740$ dengan p-value sebesar 0,002 . Terlihat bahwa nilai $\mathrm{p}=0,002<\alpha(0,05)$, Ada hubungan yang signifikan antara dukungan keluarga dengan kecemasan postpartum.

Simpulan : Ada hubungan yang signifikan antara dukungan keluarga dengan kecemasan postpartum. Semakin tinggi dukungan keluarga maka tingkat kecemasan postpartum rendah.
\end{abstract}

Kata Kunci: Kecemasan Postpartum, Asuhan Postpartum, Cross Sectional

\begin{abstract}
Background : Postpartum anxiety is still a problem for the people in Indonesia and is often undetectable due to lack of reporting. This anxiety results in maternal psychological disorders, disrupting relationships with husbands and children, disturbances in infant growth and development.

The Aim : This study aims to detemine the relationship between family support with the incidence of postpartum anxiety

Method : This descriptive correlation study was carried out by cross sectional. The population of this study were all postpartum mothers at Budi Mulia Medica Maternity Clinic from September to October 2018 with a total of 120 people, the sampling technique used was Accidental Sampling where the respondents found 27 respondents. Data is taken using primary data and secondary data. Data
\end{abstract}


collection tools in the form of questionnaires. Analysis of univariate and bivariate data using kendall tau.

Result : Based on the Kendall Tau test, a value of $\tau=-0.740$ is obtained with a pvalue of 0.002. It was seen that $p=0.002<\alpha(0.05)$, there was a significant relationship between family support and postpartum anxiety.

Conclusions: There is an age relationship with the knowledge of young women about Breast Self Examination (BSE).

Keywords: The Postpartum Anxiety, Postpartum care, cross sectional.

\section{PENDAHULUAN}

Kecemasan postpartum merupakan masalah yang signifikan dan menjadi perhatian masyarakat sejak lama. Walaupun terkadang sering tidak terdeteksi karena minimnya pelaporan, penelitian menyebutkan bahwa sekitar 10\%-20\% wanita yang melahirkan menderita kecemasan. Kecemasan postpartum membuat penderitaan batin bagi ibu, dapat menyebabkan menurunnya fungsi sosial ibu dan kualitas hidupnya. Penelitian terbaru juga mengatakan bahwa ibu yang kecemasan dapat menyebabkan gangguan emosional dan kognitif pada bayinya yang baru lahir. Suatu penelitian mengatakan bahwa kecemasan terjadi dua kali lipat lebih tinggi pada wanita yang hidupnya dalam kemiskinan, sekitar 22\%-34\% dari populasi (Andri, 2010).

Motzfeldt Tahun 2013 mengatakan bahwa angka prevalensi kecemasan postpartum secara global adalah antara 10-15\% (Motzfeldt, 2013). Sebagian negara melaporkan hanya sedikit insiden kecemasan postpartum namun sebagian negara melaporkan kejadian lebih banyak (Annur, 2014). Berdasarkan laporan WHO diperkirakan wanita melahirkan yang mengalami kecemasan postpartum ringan berkisar 10 per 1000 kelahiran hidup dan kecemasan postpartum sedang atau berat berkisar 30 sampai 200 per 1000 kelahiran (Salma, 2012).

Persoalan mengenai penyebab dari kecemasan postpartum adalah sulit dan belum dijawab secara jelas, tetapi sejumlah faktor perlu mendapat perhatian. Faktor - faktor fisiologis, terutama perubahan-perubahan endokrin, sudah lama dianggap berperan dalam kecemasan postpartum karena sudah lama diketahui bahwa perubahan-perubahan hormon secara besar-besaran terjadi sesudah melahirkan dan selama "Periode Latensi", yaitu 2 hari yang biasanya terjadi sebelum timbulnya kecemasan (Semium, 2006).

Penjelasan psikologis mengemukakan bahwa kecemasan postpartum disebabkan oleh konflik-konflik yang tidak terpecahkan, serta kepribadian terhadap kegagalan dan kontrol pribadi dan terjadinya peristiwa-peristiwa hidup yang menimbulkan stress serta dukungan sosial yang kurang (Andri, 2010).

Pada ibu yang mengalami kecemasan pasca persalinan, minat dan ketertarikan terhadap bayinya berkurang sehingga tidak berespons positif terhadap bayinya. Ibu yang sedang mengalami kecemasan tidak mampu mengenali kebutuhan bayinya, tidak mampu merawat bayinya secara optimal akibatnya kondisi kesehatan dan kebersihan bayinya menjadi tidak optimal (Namora, 2009). 
Ibu yang mengalami kecemasan tidak bersemangat menyusui bayinya sehingga pertumbuhan dan perkembangan bayi tidak seperti bayi-bayi dengan ibu yang sehat. Anak-anak dengan ibu yang mengalami kecemasan pasca melahirkan dapat mengalami gangguan perkembangan emosi, terutama bila kondisi ibu tidak diatasi. Anak-anak sering sulit mengekspresikan perasaannya dan sulit berpartisipasi dalam aktivitas sosial. Sebagian tetap menutup diri dan menyimpan perasaannya (Namora, 2009).

Mengingat besarnya dampak dari kecemasan postpartum baik pada ibu maupun bayi, maka dari itu penulis tertarik untuk melakukan penelitian mengenai hubungan dukungan keluarga dengan kejadian kecemasan postpartum di Klinik Budi Mulia Medika.

Berdasarkan latar belakang masalah yang telah diuraikan di atas, maka rumusan masalah dalam penelitian ini adalah : "Apakah ada hubungan dukungan keluarga dengan kejadian kecemasan postpartum di Klinik Budi Mulia Medika?"

Tujuan dalam penelitian ini adalah untuk mengetahui hubungan dukungan keluarga dengan kejadian kecemasan postpartum di Klinik Budi Mulia Medika.

\section{METODE PENELITIAN}

Metode yang digunakan dalam penelitian ini adalah metode deskriptif korelasi dengan pendekatan cross sectional. Populasi penelitian ini adalah semua ibu pasca bersalin di Klinik Bersalin Budi Mulia Medica pada bulan September sampai dengan bulan Oktober 2018 dengan jumlah 120 orang, teknik sampling yang digunakan adalah Accidental Sampling dimana saat penelitian dijumpai responden sebanyak 27 responden. Alat pengumpulan data pada penelitian ini adalah menggunakan kuesioner sebagai daftar pertanyaan yang sudah tersusun dengan baik, responden memberikan jawaban dengan memberikan tanda-tanda tertentu. Metode pengumpulan data yang peneliti gunakan adalah data primer yaitu kuesioner yang disebarkan kepada responden, sedangkan data sekunder adalah data jumlah ibu bersalin di medical record Klinik Budi Mulia Medika. Dalam penelitian ini uji analisis data yang digunakan adalah Korelasi Kendall Tau.

\section{HASIL PENELITIAN DAN PEMBAHASAN}

Tabel 1. Distribusi Frekuensi Berdasarkan Umur Responden

\begin{tabular}{cccc}
\hline No & Umur & Frekuensi & $\begin{array}{c}\text { Prosentase } \\
(\boldsymbol{\%})\end{array}$ \\
\hline 1 & $<20$ Tahun & 4 & $14,8 \%$ \\
2 & 20-35 Tahun & 22 & $81,5 \%$ \\
3 & $>$ 35 Tahun & 1 & $3,7 \%$ \\
& Jumlah & 27 & $100 \%$ \\
\hline
\end{tabular}

Pada tabel 1 menunjukkan sejumlah 22 responden $(81,5 \%)$ berumur 20 35 tahun, 4 responden $(14,8 \%)$ berumur $<20$ tahun dan 1 responden $(3,7)$ berumur $>35$ tahun). 
Jurnal Kebidanan Indonesia. Vol 10 No 1. Januari 2019 (30 -38)

Tabel 2. Distribusi Frekuensi Berdasarkan Paritas Responden

\begin{tabular}{llccc}
\hline No & & Paritas & Frekuensi & Prosentase (\%) \\
\hline 1 & P1 & & 10 & $37,0 \%$ \\
2 & P2 & & 11 & $40,7 \%$ \\
3 & P3 & & 6 & $22,3 \%$ \\
& & Jumlah & 27 & $100 \%$ \\
\hline
\end{tabular}

Pada tabel 2 menunjukkan jumlah responden dengan paritas multipara sebanyak 17 responden (63\%) sedangkan jumlah responden dengan paritas primipara sebanyak 10 responden (37\%).

Tabel 3 Distribusi Frekuensi Berdasarkan Dukungan Keluarga

\begin{tabular}{|c|c|c|c|}
\hline No & Dukungan Keluarga & Frekuensi & Prosentase (\%) \\
\hline 1 & Rendah & 2 & $7,4 \%$ \\
\hline 2 & Sedang & 3 & $11,1 \%$ \\
\hline 3 & Tinggi & 22 & $81,5 \%$ \\
\hline & Jumlah & 27 & $100 \%$ \\
\hline
\end{tabular}

Pada tabel 3 menunjukkan sejumlah 22 responden (81,5\%) memiliki dukungan keluarga yang tinggi, sedangkan yang mendapat dukungan sedang sejumlah 3 responden $(11,1 \%)$, dan yang mendapat dukungan rendah sejumlah 2 responden $(7,4 \%)$.

Tabel 4 Distribusi Frekuensi Berdasarkan Kecemasan Postpartum

\begin{tabular}{|c|c|c|c|}
\hline No & Dukungan Keluarga & Frekuensi & Prosentase $(\%)$ \\
\hline 1 & Rendah & 19 & $70,4 \%$ \\
\hline 2 & Sedang & 6 & $22,2 \%$ \\
\hline 3 & Tinggi & 2 & $7,4 \%$ \\
\hline & Jumlah & 27 & $100 \%$ \\
\hline
\end{tabular}

Pada Tabel 4 menunjukkan sejumlah 19 responden (70,4\%) mengalami kecemasan postpartum ringan, 6 responden (22,2\%) mengalami kecemasan postpartum sedang dan 2 responden $(7,4 \%)$ mengalami kecemasan postpartum.

Tabel 5.Tabulasi Silang Hubungan Dukungan Keluarga dengan Kecemasan Postpartum

\begin{tabular}{|c|c|c|c|c|c|c|c|c|c|c|}
\hline \multirow{3}{*}{$\begin{array}{c}\text { Dukungan } \\
\text { Keluarga }\end{array}$} & \multicolumn{8}{|c|}{ Kecemasan Postpartum } & \multirow{3}{*}{ 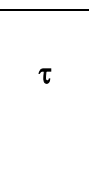 } & \multirow{3}{*}{$\begin{array}{c}P \\
\text { Value }\end{array}$} \\
\hline & \multicolumn{2}{|c|}{ Berat } & \multicolumn{2}{|c|}{ Sedang } & \multicolumn{2}{|c|}{ Ringan } & \multicolumn{2}{|c|}{ Total } & & \\
\hline & $\mathrm{F}$ & $\%$ & $\mathrm{~F}$ & $\%$ & $\mathrm{~F}$ & $\%$ & $\mathrm{~F}$ & $\%$ & & \\
\hline Rendah & 1 & 50,0 & 1 & 50,0 & 0 & 0,00 & 2 & 100 & & \\
\hline Sedang & 1 & 33,3 & 2 & 66,3 & 0 & 0,00 & 3 & 100 & - & 0,002 \\
\hline Tinggi & 0 & 0,00 & 3 & 13,6 & 19 & 86,4 & 22 & 100 & 0,740 & 0,002 \\
\hline Total & 27 & 70,4 & 6 & 22,2 & 2 & 7,40 & 27 & 100 & & \\
\hline
\end{tabular}


Sejumlah 2 responden dengan dukungan keluarga rendah mengalami kecemasan postpartum berat 1 responden (50\%) dan sedang 1 responden (50). Responden dengan dukungan keluarga sedang berjumlah 3 responden yang mengalami kecemasan postpartum berat 1 responden $(33,3 \%)$ dan sedang 66,3 responden (66,3\%). Responden dengan dukungan keluarga tinggi berjumlah 22 responden yang mengalami kecemasan postpartum sedang 3 responden $(13,6 \%)$ dan ringan 19 responden $(86,4 \%)$.

Berdasarkan hasil tersebut dapat dilihat bahwa ibu yang mengalami kecemasan postpartum berat lebih banyak pada ibu dengan dukungan keluarga rendah dari pada dukungan keluarga sedang ataupun tinggi.

Berdasarkan uji Kendal Tau didapatkan nilai $\tau=-0,740$ dengan p-value sebesar 0,002 . Terlihat bahwa nilai $p=0,002<\alpha(0,05)$, ini berarti ada hubungan yang signifikan antara dukungan keluarga dengan kecemasan postpartum pada ibu pasca melahirkan di Klinik Budi Mulia Medika Palembang. Hubungan di atas merupakan hubungan yang kuat dengan arah negatif, artinya jika dukungan keluarga semakin tinggi maka kecemasan postpartum yang dialami ibu semakin ringan.

Penelitian terhadap 27 responden diperoleh hasil bahwa sejumlah 22 responden $(81,5 \%)$ memiliki dukungan keluarga yang tinggi, sedangkan yang mendapat dukungan sedang sejumlah 3 responden $(11,1 \%)$, dan yang mendapat dukungan rendah sejumlah 2 responden $(7,4 \%)$. Hasil penelitian memberikan gambaran bahwa sebagian besar ibu memperoleh dukungan keluarga yang tinggi.

Ibu postpartum sangat membutuhkan dukungan keluarga. Menceritakan perasaan dan perubahan hidup yang dirasakan kepada pasangan atau orang tua akan membantu mengurangi kesulitan yang dihadapi. Dukungan emosional dari lingkungan dan keluarga akan membantu dalam mengatasi rasa frustasi yang dialami.

Dukungan keluarga yang diberikan dalam bentuk membantu merawat bayi, pekerjaan sehari-hari, materi, memberikan perhatian, penghargaan dan empati kepada ibu dapat menurunkan tingkat kecemasan postpartum. Keluarga memberikan nasehat dan informasi yang dapat menjadikan individu lebih mampu untuk mengatasi sesuatu.(Saleha, 2009).

Suami merupakan orang yang paling berpengaruh dalam pemberian dukungan untuk meringankan kecemasan pada masa postpartum. Ibu postpartum terkadang memiliki sensitifitas yang luar biasa sehingga emosinya tidak terkontrol dengan baik. Suami yang kurang perhatian akan menjadi problem tersendiri dan membuat ibu merasa tertekan. Suami yang baik adalah suami yang memanjakan istrinya dengan cara yang baik.

Kepandaian suami dalam menjaga segala bentuk komunikasi dengan istrinya akan membuat sang istri merasa senang. Suami dan keluarga yang memberikan dukungan rendah dapat mempengaruhi ketidaknyamanan ibu dan mengganggu aktivitas ibu dalam kehidupan sehari-hari karena belum merasa senang, puas, aman dan nyaman setelah melahirkan bayinya sehingga akan mempengaruhi psikologi ibu dalam merawat bayi sehingga perawatan pada bayi menjadi kurang maksimal.(Amrin,2010). 
Dukungan keluarga memiliki banyak kegunaan diantaranya adalah ibu merasa lebih diperhatikan keluarga, dapat mengurangi rasa kurang percaya diri, memberikan harapan, dapat mengeluarkan segala perasaan dan masalah, merasa diterima dalam keluarga dan disayang dalam keadaan apapun.(Lubis, 2009).

Peneliti berharap melalui dukungan keluarga dapat mengurangi stress yang dialami ibu postpartum sehingga mereka dapat lebih optimis dan percaya diri dalam melawan kecemasan tersebut.

Penelitian ini didapatkan hasil bahwa sejumlah 19 responden $(70,4 \%)$ mengalami kecemasan postpartum ringan, 6 responden $(22,2 \%)$ mengalami kecemasan postpartum sedang dan 2 responden $(7,4 \%)$ mengalami kecemasan postpartum berat. Hasil penelitian ini memberi gambaran bahwa sebagian besar ibu mengalami kejadian kecemasan pasca persalinan yang ringan.

Menurut hasil penelitian diketahui bahwa sebagian ibu pasca persalinan yang menderita kecemasan postpartum sedang adalah primipara. Kecemasan pasca persalinan ini lebih banyak ditemukan pada perempuan primipara, mengingat bahwa peran seorang ibu dan segala yang berkaitan dengan bayinya merupakan situasi baru bagi dirinya dan dapat menimbulkan stress. Penelitian Le Masters 2013 mengatakan bahwa responden pasangan muda dari kelas sosial menengah mengalami krisis setelah kelahiran bayi pertama.

Sebagian ibu postpartum mengalami kesulitan dalam melakukan pekerjaan rumah sehingga ibu sering lelah dalam merawat bayi dan melakukan pekerjaan rumah sehari-hari. Pada ibu primipara, perubahan peran terjadi sebelumnya ibu adalah seorang istri tapi sekarang berperan juga sebagai seorang ibu dengan bayi yang sangat membutuhkannya.

Seorang multipara sebelumnya sudah pernah mempunyai tanggung jawab sebagai seorang ibu dan pernah merawat bayi sehingga tidak mengalami kesulitan dalam masa nifas.(Lubis, 2009).

Ibu yang mengalami kecemasan pasca persalinan, minat dan ketertarikan terhadap bayinya berkurang sehingga tidak berespons positif terhadap bayinya. Ibu yang sedang kecemasan tidak mampu mengenali kebutuhan bayinya, tidak mampu merawat bayinya secara optimal akibatnya kondisi kesehatan dan kebersihan bayinya menjadi tidak optimal. Ibu yang kecemasan juga tidak bersemangat menyusui bayinya sehingga pertumbuhan dan perkembangan bayi tidak seperti bayi-bayi dengan ibu yang sehat. Anak-anak dengan ibu yang mengalami kecemasan pasca melahirkan dapat mengalami gangguan perkembangan emosi, terutama bila kondisi ibu tidak diatasi. Anak-anak sering mengalami kesulitan dalam mengekspresikan perasaannya dan sulit berpartisipasi dalam aktivitas sosial. Sebagian tetap menutup diri dan menyimpan perasaannya.

Menurut penelitian Yuwono dalam Lubis 2009 mengatakan bahwa anakanak dari ibu yang mengalami kecemasan pasca persalinan dapat mengalami gangguan perilaku pada usia 3 tahun, artinya pada usia 3 tahun sudah dapat dideteksi adanya perilaku yang berbeda dibandingkan dengan anak seusianya. Anak-anak tersebut juga dapat mengalami rendahnya fungsi berfikir pada usia 4 tahun, yang biasanya dapat terdeteksi ketika anak mulai masuk sekolah. Hal ini memberi gambaran pula bahwa kecemasan postpartum dapat berdampak negatif dalam jangka panjang bagi keluarga.(Lubis,2009). 
Ibu yang mengalami kecemasan postpartum apabila tidak mendapatkan asuhan yang baik dapat meningkatkan resiko percobaan bunuh diri. Ibu yang mengalami kecemasan pasca persalinan memiliki pikiran untuk bunuh diri. Perasaan kesepian dan ketidakberdayaan adalah faktor yang sangat besar untuk seseorang melakukan bunuh diri. Ibu yang menderita kecemasan pasca persalinan terkadang merasa putus asa sehingga mereka memutukan membunuh dirinya sendiri.

Kecemasan pasca persalinan dapat menjadi penyakit yang sangat mengganggu kehidupan sehari-hari, namun kemungkinan untuk mengobati individu. Kadang-kadang kecemasan pasca persalinan juga bisa hilang dengan sendirinya tanpa harus menjalani pengobatan. Pada kasus yang berat diperlukan terapi dan pengobatan yang efektif untuk mengurangi kecemasan, namun pada kasus kecemasan ringan dan sedang dapat melakukan terapi terhadap diri sendiri untuk mengurangi gejala-gejala kecemasan.(Lubis,2009).

Pada penelitian ini didapatkan hasil bahwa sejumlah 2 responden dengan dukungan keluarga rendah mengalami kecemasan postpartum berat 1 responden (50\%) dan sedang 1 responden (50\%). Responden dengan dukungan keluarga sedang berjumlah 3 responden yang mengalami kecemasan postpartum berat 1 responden $(33,3 \%)$ dan sedang 66,3 responden $(66,3 \%)$. Responden dengan dukungan keluarga tinggi berjumlah 22 responden yang mengalami kecemasan postpartum sedang 3 responden $(13,6 \%)$ dan ringan 19 responden $(86,4 \%)$.

Berdasarkan hasil tersebut menunjukkan bahwa ibu yang mengalami kecemasan postpartum berat lebih banyak pada ibu dengan dukungan keluarga rendah dari pada dukungan keluarga sedang maupun tinggi. Rendahnya dukungan suami dan keluarga akan meningkatkan kejadian kecemasan pasca persalinan pada ibu.

Berdasarkan uji Kendal Tau, telah didapatkan nilai $\tau=-0,740$ dengan pvalue sebesar 0,002 . Terlihat bahwa nilai $p=0,002<\alpha(0,05)$, ini berarti dapat disimpulkan bahwa ada hubungan yang signifikan antara dukungan keluarga dengan kecemasan postpartum. Hubungan di atas merupakan hubungan yang kuat dengan arah negatif, artinya jika dukungan keluarga semakin tinggi maka kecemasan postpartum yang dialami ibu semakin ringan.

Penelitian ini didapatkan hasil bahwa dukungan keluarga memiliki peran yang sangat penting terhadap kejadian kecemasan pasca persalinan pada seorang ibu. Ibu dengan dukungan keluarga rendah memiliki kecendrungan terjadinya kecemasan pasca persalinan yang lebih besar dibandingkan dengan seorang ibu yang memperoleh dukungan yang tinggi dari suami dan keluarga. Suami, keluarga serta banyaknya kerabat yang membantu pada saat kehamilan, persalinan dan pasca peralinan, beban seorang ibu karena kehamilannya sedikit banyak berkurang. Dapat disimpulkan bahwa semakin rendah dukungan keluarga yang diberikan, maka akan mempengaruhi terjadinya kecemasan.

Dukungan yang diberikan pada ibu akan berpengaruh dalam menjalani masa nifas yaitu adanya tanggung jawab ibu dalam mengurus bayi dan rumah tangga. Adanya dukungan keluarga yang tinggi maka tanggung jawab ibu akan lebih ringan dibandingkan dengan tanggung jawab ibu yang mendapat dukungan keluarga rendah. Hasil penelitian ini sesuai dengan yang dikemukakan oleh Elvira 
dalam Marshall (2004), bahwa ibu yang mendapat dukungan keluarga rendah setelah melahirkan dapat meningkatkan resiko untuk mengalami suatu kecemasan. Menghindari masalah ini, maka perempuan yang akan melahirkan harus mendapat perhatian cukup dari keluarga, terutama suaminya. Suami dan keluarga bisa mempelajari berbagai referensi tentang perawatan bayi baru lahir yang digunakan sebagai panduan dalam membantu ibu merawat bayi (Lubis, 2009).

\section{SIMPULAN DAN SARAN}

\section{Simpulan}

Umur responden mayoritas berumur 20 - 35 tahun dengan jumlah persentase $81,5 \%$. Paritas responden mayoritas dengan paritas multipara sebanyak 17 responden 63\%. Dukungan keluarga mayoritas tinggi yaitu sebanyak 22 responden $81,5 \%$. Kecemasan postpartum mayoritas ringan yaitu sebanyak 19 responden $70,4 \%$. Ada hubungan yang signifikan antara dukungan keluarga dengan kecemasan postpartum pada ibu pasca melahirkan di Klinik Budi Mulia Medika Palembang.

\section{Saran}

Bagi tenaga kesehatan khususnya bidan agar memberikan edukasi yang komprehensif kepada suami dan keluarga tentang pentingnya dukungan untuk ibu dimulai saat masa kehamilan, persalinan dan pasca persalinan. Bagi peneliti selanjutnya diharapkan peneliti selanjutnya agar melakukan penelitian di lokasi lain yang memiliki karakteristik berbeda dengan tempat yang dilakukan penelitian serta mengambil responden lebih banyak dan mempertimbangkan aspek lain seperti aspek fisik, aspek biologis. Aspek psikologis dan faktor-faktor selama proses persalinan. Bagi responden diharapkan responden dapat menambah wawasan dengan menanyakan informasi kepada tenaga kesehatan dan menyadari bahwa kecemasan postpartum adalah hal yang alami dan sebagian besar ibu postpartum akan mengalaminya.

\section{DAFTAR PUSTAKA}

Andri. 2010. Kecemasan Pasca Melahirkan https://www.kompasiana.com/psikosomatik_andri/54fff4458133110b68f a7060/kecemasan-pasca-melahirkan?page=all. Diakses 19 September 2018 jam 10.30 WIB.

Annur Hikmah Basri, Andi Zulkifli,M.Tahir Abdullah. 2014. Efektivenness Of Psychoeducation On Postpartum Depression in RSIA Sitti Fatimah and RSIA Pertiwi Makassar 2014. http://pasca.unhas.ac.id/jurnal/files/f0c9cd5d464f70d10bb4e75f2c0da1 la.pdf Diakses 20 September 2018 jam 20.30 WIB.

Amrin, A.2010.Kiat-kiat melahirkan tanpa rasa sakit yang menakutkan. Yogyakarta : Gerailmu.

Lubis, N. 2009. Kecemasan Tinjauan Psikologis. Jakarta: Kencana Prenada Media Group. 
Jurnal Kebidanan Indonesia. Vol 10 No 1. Januari 2019 (30 -38)

Machfoedz.2007. Metodologi Penelitian. Yogyakarta : Fitramaya

Motzfeldt I.,Andreasen S., Pedersen A.L.,Pedersen M.L. 2013. Prevalence of Postpartum depression in Nuuk. Greenland-a cross-sectional study using Edinburgh Postnatal Depression Scale. Int J Circumpolar Health.2013.72:21114.

Namora Lumonggalubis.2009.Kecemasan Tinjauan Psikologis. Kencana: Jakarta.

Nursalam.2008.Konsep dan Penerapan Metodologi Penelitian Ilmu Keperawatan.Jakarta : Salemba Medika.

Saleha, S.2009.Asuhan Kebidanan Pada Masa Nifas.Jakarta : Salemba Medika.

Salma.2012.5 Penyebab Utama Kematian Ibu di Indonesia. Majalah Kesehatan.http://majalahkesehatan.com. Diakses 01 Oktober 2018 jam 10.30 WIB.

Semium Yustinus, OFM.2006.Kesehatan Mental. Kanius.Yogyakarta. 